uncertainties for the staff had made Darenth Park's closure party an occasion for mixed emotions. For those whose involvement had been comparatively recent, celebration of a massive administrative project successfully completed overshadowed the sadness felt by staff from earlier times for the passing of a now unfashionable residential community and its way of life, which had been not all bad for patients and themselves alike. When and where might old friends ever meet again, with their base gone?

The final visits to Darenth Park, after the last patients had departed, invaded the world of dreams with a surreal scenario. Entering to clear my remaining documents, I encountered unexpectedly a personable young man seated at my desk. He invited me to follow and took me down to the boiler room in the basement, well known as a refuge for missing patients in the past. Here was a scene of total devastation, the area filled with rubble. Britten's War Requiem, fortissimo, resounded through the space with poignant splendour, rolling back the years. A young woman in front of an altar repeated gestures suggesting silent despair.

One had not been asleep. The explanation was that a newly closed mental handicap hospital, as reported in the press, had suggested itself as an ideal location for filming the futility of destruction embodied in Wilfrid Owen's first World War poetry set by Benjamin Britten. Trenches and a field hospital had been recreated. Sir Laurence Olivier had played there the previous day. The Bach Choir was participating. Hospital staff were engaged as extras. Derek Jarman's film War Requiem, shot entirely in the buildings and grounds of Darenth Park Hospital, is due to open in the West End in January 1989, will be televised Easter weekend and become available for purchase on CDV for anyone who would like an unique memento of one of our large psychiatric hospitals.

(Consultant Psychiatrist

P. Grahame Woolf at Darenth Park Hospital 1963-88)

\section{Families in an in-patient setting}

\section{DeAR Sirs}

Dr Roger Kennedy's interesting article on the treatment of child abuse in an in-patient setting (Bulletin, September 1988, 12, 361-366) requires modification of its introductory statement.

The Cassel Hospital was, I believe, the first hospital to admit families for observation and treatment, primarily psychotherapeutic. It is not, however, the only one. In a symposium on families in hospital, one of the articles ${ }^{1}$ describes the establishment in Fife, in 1975 , of a purpose-built residential unit for families. Accommodation for three families is part of the residential facilities of a department of child and family psychiatry and these are situated in the grounds of a psychiatric hospital (Stratheden Hospital, Coupar, Fife).

\section{Hepburn Gardens}

J. D. HAldane

St Andrews, Fife

\section{Reference}

${ }^{1}$ Haldane, J. D., MoCluskey, U. \& Peacey, M. (1980) Development of a residential facility for families in Scotland: prospect and retrospect. International Journal of Family Psychiatry, 1, 357-371.

\section{$S P R I G$}

\section{Dear Sirs}

In the article by Wanda Hudson re SPRIG (Bulletin, September 1988) reference was made to my having written to "72 Scottish Chairpersons of all political parties". Lest colleagues in the South are confused, can I point out that this should have read "72 Scottish Members of Parliament". Although politically enlightened North of the Border, we do not as yet have 72 political parties.

Dykebar Hospital

J. M. Dingwall 